\title{
A idéia de história como progresso: um meio para a humanidade
}

Resumo: Este artigo discorre acerca de como a idéia de progresso está presente no conceito "história". A aproximação entre os conceitos de progresso e história apóia-se num texto de Kant: Idéia de uma história universal de um ponto de vista cosmopolita. Pretende-se demonstrar como o idealismo transcendental tem uma compreensão de história que aponta para o futuro e não para o passado e indica como o idealismo alemão pode e teve de se apropriar do próprio conceito de história e o desenvolver. A noção que Kant lança de insociável sociabilidade humana representa o suporte e o ponto de partida para a análise e para a incursão da noção de progresso e desenvolvimento no conceito "história".

Palavras-chave: razão, história, progresso, sujeito.

A noção de história como progresso permeia a obra de Kant não de maneira tematizada, mas como um pano de fundo inaudito, podendo ser trazida à fala numa compreensão. Compreensão esta que se pretende expor neste trabalho. Tal história é uma Idéia de uma história universal de um ponto de vista cosmopolita e visa a reunir o acontecimento do homem num todo desde um ponto de vista cosmopolita, ou seja, a totalidade dos fins ao qual tende tal história. Partindo de uma determinada compreensão de homem, pode-se olhar para o passado, desde que se o apreenda num progressivo e lento movimento do homem em direção a si mesmo até o esclarecimento do mesmo, para, então, poder lançar essa história num futuro possível (concorde ao movimento de desenvolvimento do homem que lhe é próprio). Se se apreende o homem em sua natureza e se a reúne numa idéia de humanidade, e se se pontua um fundo comum que reúne o que se apresenta no 'ser-homem', tal plano parece bem acertado. "Uma tentativa filosófica de elaborar a história do mundo segundo um plano da natureza que vise à perfeita união çivil na espécie humana deve ser considerada possível e mesmo favorável a este propósito da natureza" ${ }^{2}$.

\footnotetext{
' Graduanda em filosofia pela UFPR e bolsista do PET-Filosofia,

${ }^{2}$ KANT, Immanuel. Idéia de uma história universal de um ponto de vista cosmopolita, nona proposição, pg. 22
} 
Ao fundo dessa planificação da história está a noção de um esclarecimento do homem para si mesmo. Se o apreende em suas condições de possibilidade - as quais permitem um olhar histórico sobre ele - em cujo fundamento a liberdade encontra o seu lugar pois se a toma como constitutiva da humanidade que lhe contém. A possibilidade de tal história é, desse modo, a demonstração da possibilidade mesma da liberdade, ou da compreensão de um homem livre, cuja expressão máxima é o esclarecimento. Ela é, ao mesmo tempo, uma história moral do homem à medida que é uma história de seu poder-ser livre. Mesmo o desenvolvimento de uma teoria crítico-transcendental como crítica da razão pura tem como fundo tal liberdade, pois, ao fim e ao cabo da delimitação e do critério do uso possível da razão, encontra-se a liberdade como fundamento, enquanto esta é uma idéia da Razão.

Furto-me aqui da tarefa de descrever como a razão especulativa encontra em si mesma a liberdade concebendo-a como uma idéia. Para o presente texto basta admitir-se que a razão concebe idéias que são transcendentais, e que a liberdade é uma idéia da razão, fundamental para se estabelecer a moral. Pode-se entender por transcendental a nomeação do que permite ao homem o uso de suas faculdades, como o fundamento do mesmo $^{3}$. Uma idéia transcendental da razão seria aquela que reúne e dispõe as condições desde as quais algo (ou seja, algo posto e determinado por uma condição. Em suma, um condicionado) torna-se possível. No caso da moral, uma idéia transcendental como a liberdade é o que reúne e estabelece as condições para que a moral seja racionalmente determinada por ser a condição primeira de uma causalidade cuja causa é a própria razão. Pressupomos, então, a liberdade como o fundo de toda ação num plano moral.

A história do homem é a história da liberdade, isto é, a história de seu poder-ser livre. Por isso mesmo ela é moral, o que se assume, finalmente, como esclarecimento. A liberdade é, contudo, uma idéia da razão. Por sua vez, a idéia de liberdade é um conceito fundamental desde o qual a possibilidade de um homem esclarecido se dá num todo moral. Ora, a inserção do homem num todo moral requer o seu esclarecimento como meio de tal inserção, transformando-o, finalmente, no que ele mesmo é, ou seja, um ser-racional. A exigência de tal inserção é, pelo seu esclarecimento, a assunção da liberdade de sua vontade. A moral como história é, desse modo, a história da liberdade da vontade do homem. A função de tal moral

\footnotetext{
${ }^{3}$ Conceito esse tratado mais detidamente pelo autor na Critica da Faculdade de Julgar.
} 
é delimitar, determinar o âmbito de possibilidades do agir, de como agir, instruindo e ao mesmo tempo possibilitando a ação, que requer um móbile e uma determinação que instigue o agir. Para que uma ação seja moral, implica-se que seja determinada não em vista de um móbile da vontade, externo à própria vontade, mas sim de uma pura determinação da vontade pela razão, tornando esta uma vontade livre.

Em Idéia de uma história universal de um ponto de vista cosmopolita, de Kant, há a seguinte afirmação: "A natureza quis que o homem tirasse inteiramente de si tudo que ultrapassa a ordenação mecânica de sua existência animal e que não participasse de nenhuma felicidade ou perfeição senão daquela que ele proporciona a si mesmo, livre do instinto, por meio da própria razão" ${ }^{4}$. Nessa fala pode-se apreender que o homem se insere numa natureza; não só isso, que ele tem uma natureza própria. Entender o homem dotado e inserido numa natureza, contudo, extrapola a ordenação mecânica natural, a ordenação por instinto constitutiva da animalidade, extrapola mesmo a determinação causal-temporal numa séria constitutiva da ordem natural da natureza. Enquanto pertencente à natureza, o homem extrapola a mera animalidade. Há nele algo de animal, mas isso que nele seria animal, o corpo, não é a pura animalidade presente no animal. Ele é dotado de razão, i. e., proporciona para si mesmo, desde si, as condições necessárias para sua "existência-subsistência". Ele retira de suas disposições naturais, que aqui significam constitutivas, o modo e o meio de estabelecer, para si, suas condições ideais. Ou seja, as condições pelas quais desenvolvem-se suas próprias possibilidades são determinadas pelas mesmas. Estas são, de algum modo, concordes com a própria natureza.

Segue o texto dizendo: "A natureza não faz verdadeiramente nada supérfluo e não é perdulária no uso dos meios para atingir os fins. Tendo dado ao homem a razão e a liberdade da vontade que nela se funda, a natureza forneceu um claro indício de seu propósito quanto à maneira de dotá-lo. Ele não deveria ser guiado pelo instinto, ou ser provido e ensinado pelo conhecimento inato; ele deveria, antes, tirar tudo de si mesmo" 5 . Sendo capaz de tirar tudo de si mesmo, esse homem que é dotado de um poder por um lado extrapola a mera animalidade, o instinto, e por outro não é onisciente, dotado de um conhecimento inato. Sendo assim, ele (o homem) precisa aprender, precisa desenvolver - conforme o plano da natureza - as suas disposições constitutivas, usando, do modo mais

\footnotetext{
${ }^{4}$ idem. terceira proposição

${ }^{5}$ ibidem, terceira proposição, pg. 12
} 
adequado possível, o seu poder (possibilidade). Esse movimento do homem em direção a si é, do ponto de vista do esclarecimento, histórico. Ele mesmo conduziu-se, por um processo natural, ao esclarecimento por conta do caráter próprio do homem, o qual, agora, requer uma tomada de posição frente tal evolução, frente a sua liberdade, a liberdade da vontade.

Por ser o homem dotado de uma razão, esta pode e, por isso mesmo, deve ser desenvolvida em sua plenitude. Se, por um lado, a ciência é o modo e o meio pelo qual essa razão se amplia maximamente no âmbito do conhecimento cujo limite e procedimento descrevem-se na Crítica da Razão Pura, por outro lado essa razão tem, no âmbito da ação, um uso que é moral e que se funda na liberdade da vontade. O homem é dotado de uma livre vontade no agir cujo fundamento é a razão. Essa disposição desenvolve-se plenamente numa moral racionalmente constituída pois, se a liberdade da vontade encontra seu fundamento na razão, suas determinações devem ser racionais permitindo e até exigindo uma moral que se constitua racionalmente. A moral seria o modo e o meio de se desenvolver a disposição da razão enquanto o homem é capaz de agir, cuja ação é fundada na liberdade da vontade, o que delimita o poder e o modo de ação deste homem que se esclarece a si mesmo no âmbito moral.

A liberdade da vontade, pois, funda-se na razão. Ora, a rigor, a vontade por si mesma não é livre. A vontade é desejante ou, mais precisamente, é a faculdade de desejar, o que condiciona toda a ação. Se a vontade é a faculdade do querer, todo o querer quer algo. Concebe-se, contudo, um homem cuja possibilidade é tirar de si mesmo as condições pelas quais ele é. Admitir, desse modo, um querer que seja conduzido e determinado por algo, cujo móbile é externo a ele homem enquanto serracional livre, seria admitir um homem condicionado por algo outro que não ele mesmo, implicando, assim, uma vontade sempre determinada por um instinto, por um hábito, por um costume. O hábito ou o costume, contudo, sendo eles constitutivos de uma vida e de um mundo eminentemente humanos, não podem ser instintivos e, por partilharem do humano, extrapolam a pura mecanicidade. Quer dizer, mesmo o hábito e o costume são determinados racionalmente embora não assumidamente pela razão, o que requereu ao Aufklärung a distinção entre maior e minoridade. Sapere Aude!, incita Kant.

A ação e a vontade são, no plano do hábito e do costume, conduzidas e determinadas por interesses, por inclinações, por uma vontade que não assume seu poder-ser livre mas parte de afecções sensíveis. Saindo o homem de um estado de indiferença, é tocado e mobilizado a uma ação, 
condicionando a vontade (enquanto querer). Entretanto, um homem dotado de razão que se abandona ao sabor do pendor e da inclinação não está à altura de si mesmo, não toma para si, desde si, a tarefa de desenvolver as condições que permitam a ele mesmo em sua racionalidade se desenvolver, fazendo dele aquilo que ele mesmo é, um ser-racional, abandonando-se, desse modo, ao sabor das circunstâncias e das paixões e interesses que tomam a alma. Tal abandono, contudo, não é destituído de racionalidade; é esta que não é assumidamente o determinante do agir.

Com efeito, esse ser-racional é eminentemente moral. Quer dizer, se ele é dotado de razão, se age conforme um hábito também racional, deve assumir sua racionalidade esclarecendo-se, tornando-se aquilo que é, um ser-racional. Tal exigência é, por si só, moral, um dever. Dever esse desde o qual suas próprias disposições se realizam. O homem, como um ser agente, deve se dispor na ação como a causa de sua ação e não encontrar em seu agir uma causa outra tal como um interesse, uma inclinação ou um pendor do caráter. Desse modo, uma moral que determina racionalmente o âmbito de possibilidades da ação pressupõe e requer uma vontade que seja livre.

Uma vontade livre é e deve ser determinada ou condicionada pela razão. Justamente nisso consiste sua liberdade. Ora, se a liberdade é uma idéia da razão, uma vontade livre deve ser concorde à idéia de liberdade. A liberdade é, para Kant, a causa pela qual o homem tira tudo de si mesmo. Tal é uma idéia e por ser idéia, puramente racional; é a razão em seu exercício mais puro. Justamente por isso deve ser causa de uma vontade de um ser-racional que deve querer poder realizar suas disposições plenamente - o que requer, para tanto, as condições por ele mesmo determinadas. Em outros termos, a liberdade como causalidade da vontade é o meio pelo qual o homem é um fim em si mesmo. O querer dessa vontade puramente determinada pela razão quer que a razão seja capaz de exercer plena e livremente o seu poder, elevando o homem à condição de senhor, i. e., autônomo. Elevar o homem à condição de senhor significa que ele seja dono da própria vontade, digno de si em suas possibilidades: esclarecido. Esclarecer-se significa poder fazer uso de sua própria razão, do próprio entendimento sem a direção de outrem. Para tanto requer-se que se conheça quais sejam as possibilidades e o uso possível dessa Razão - Crítica da Razão Pura. Tal conhecimento de si mesmo requer justamente uma Crítica da Razão Prática, isto é, a exigência de uma moral que seja capaz de determinar a vontade como livre, concordando, assim, com o esclarecimento cuja exigência se assenta nas disposições de que o homem é dotado, desenvolvendo-as e exercendo-as plena e livremente segundo suas 
condições de possibilidade, a autonomia da razão. "Como ser-racional (e porque pertence à um mundo inteligível), o homem só pode pensar na causalidade da sua vontade sob a idéia de liberdade; porque a independência relativamente a causas determinantes do mundo sensivel (independência que a razão deve sempre atribuir a si mesma) é a liberdade. Ora, à idéia de liberdade está inseparavelmente ligado o conceito da autonomia, e à deste o princípio universal da moralidade, que, na idéia, serve de fundamento a todas as ações dos seres racionais, como a lei da natureza [serve] a todos os fenômenos" 6 .

Desse modo, é na liberdade como causalidade que uma vontade autônoma é possível. Uma vontade autônoma é, nas palavras de Kant, “a propriedade que ela tem de ser a sua própria lei (independentemente da natureza dos objetos do querer)" " . Por conseguinte, uma vontade autônoma não pode nem deve ser determinada por um objeto do querer, os quais são o interesse, a inclinação e a disposição do caráter ou do ânimo. Inclinação é "a dependência da faculdade de desejar em relação à sensação" 8 . O interesse é "a dependência de uma vontade, cujas determinações são contingentes em relação aos princípios da razão" 9 . Interesse, quando voltase para si mesmo, no sentido do esclarecimento, é um interesse afinado com a razão. Um interesse cujo mote é a satisfação de um desejo ou de uma necessidade pessoal, mesmo que não cause dano a ninguém, é já um condicionante da vontade. A possibilidade de uma vontade autônoma é o princípio da moralidade, e sua possibilidade "só poderá estar no princípio da vontade, considerado independente dos fins que podem ser alcançados pela ação; na verdade, a vontade é colocada entre o seu princípio a priori, que é formal, e seu móbil a posteriori, que é material, como no cruzamento de duas estradas, e, como tem de ser determinada, de uma maneira ou de outra, sê-lo-á necessariamente pelo princípio formal da vontade, em geral, quando uma ação é feita por dever; porque, neste caso, é-lhe retirado todo o principio material" ${ }^{10}$.

O princípio formal da vontade, para que esta seja livre, é racional (determinado pela razão). A razão é reflexionante. Por ser reflexionante refere-se ao seu objeto (a reflexão) silogisticamente, ou por meio da lógica silogística. Um juizo é compreendido dentro da lógica, e a razão opera

\footnotetext{
${ }^{6}$ KANT, Immanuel, Fundamentos da Metafisica dos costumes, 3 'secção, pg. 91.

${ }^{7}$ idem., $2^{*}$ secção, pg. 75.

${ }^{8}$ idem, pg. 41, nota 1 do autor.

${ }^{9}$ Ibidem.

${ }^{10}$ idem., $1{ }^{*}$ secção, pg. 24.
} 
logicamente segundo o princípio de não-contradição. Assim, o princípio formal da razão é um juízo da razão fundado na idéia de liberdade como causalidade. Quer dizer, o homem enquanto ser-racional pode ser a causa de sua ação. Justamente por isso ele deve sê-lo, pois é uma exigência da razão para si mesma que estabelece a condição de possibilidade, bem como o limite de todo o agir autônomo. Esse juizo formal da vontade é, segundo Kant, um imperativo, e os imperativos podem ser ou categóricos ou hipotéticos.

Um imperativo hipotético é uma máxima da vontade que tem como seu determinante um objeto do interesse - faço uma coisa por causa de outra, por exemplo, trato bem meu amigo porque ele vai me emprestar algo. A vontade, portanto, é condicionada por um interesse. Desse modo não se conquista ainda uma vontade que seja autônoma, livre. A possibilidade dessa vontade autônoma guia-se, então, por um imperativo categórico. Um imperativo categórico prescreve um dever. "Uma ação feita por dever não recebe o seu valor moral do objetivo que deve atingir, mas da máxima segundo a qual é decidida; por conseguinte, este valor não depende da realidade do objeto da ação, mas simplesmente do princípio segundo o qual a vontade se decide a concretizar esta ação; independentemente de todos os objetos da faculdade de desejar" ". Um imperativo categórico é sempre um dever segundo um princípio que reza que "devo agir sempre de tal maneira que possa também querer que a minha máxima se torne uma lei universal" 12 . Um ser-racional autônomo decide e delimita o modo e o âmbito de sua ação. Torna-se ele legislador não só de sua vontade mas partícipe de uma legislação universal que estabelece a possibilidade da moral, ou seja, o limite e o poder de toda a ação que contenha um valor moral. Quer dizer, toda a máxima moral, para que seja digna de valor, deve poder ser tomada como uma lei válida para todo o ser-racional autônomo.

Tal imperativo estabelece somente um dever à vontade pelo qual ela se realiza como livre; determina que toda a ação deve ser segundo uma vontade que queira o dever. Este nada mais prega senão uma aquiescência ao dever mesmo por corresponder às possibilidades da razão enquanto determinante de uma vontade livre, fazendo o ser-racional também livre, isto é, autônomo, realizando-se a razão em suas disposições segundo suas possibilidades e determinando as condições de possibilidade para tal realização.

\footnotetext{
"Ibidem.

${ }^{12}$ idem, pg. 26.
} 
A liberdade, contudo, não é um conceito da experiência nem tampouco pode sê-lo. Ao mesmo tempo não se pode negar que justamente este conceito puro da razão ou idéia transcendental conduz a experiência moral que se dá, enquanto ação, no âmbito causal-temporal (sensível). Toda a ação se insere na série causal-temporal, logo ela tem um objetivo em todo agir pois tem uma determinação objetiva enquanto experiência moral. A rigor, não se pode saber se uma ação foi feita por dever. Pode-se apreender na experiência moral que se age ou que alguém age conforme o dever. Não se pode também negar que há um dever prescrito à vontade em seu princípio. Se se puder, então, entender a moral num duplo sentido, como pertencente a um mundo inteligível e a um mundo sensível cujo fundamento encontra-se no mundo inteligível, bem pode-se entender a idéia de liberdade e de uma ação por dever como possível, mesmo em detrimento de todo o desejo ou inclinação. Ora, se o ser-racional age segundo o princípio dá vontade por dever, mantém-se fiel a ele, pois desse modo se é livre, sente-se livre e digno de si mesmo, enquanto um ser-racional autônomo. A coação da vontade por um dever é aquiescência à lei pois desse modo torna-se o livre ser-racional. Tal aquiescência não é, contudo, submissão. Ao contrário, é o único modo pelo qual ele se eleva em sua dignidade, assumindo suas disposições racionais enquanto um ser-racional esclarecido. Nisso consiste sua liberdade, mesmo que a sua efetivação, sua realização seja somente subjetiva.

A moral é, desse modo, uma conquista do homem que, ao conquistá-la, conquista a si mesmo pois realiza suas disposições "naturais", desenvolve sua razão criando os meios e o modo pelo qual suas possibilidades possam se efetivar. Conquistar a moralidade é então conquistar as suas próprias disposições, que, por sua vez, estabelecem a condição de possibilidade de sua realização plena. Essa moralidade se faz com vistas a fins quando o visado nada é além da conquista das condições de possibilidade desde as quais o ser-racional se realiza em sua racionalidade, em sua liberdade, em sua autonomia, isto é, um reino do fins num mundo inteligível. "Parece que a natureza não se preocupa com que ele [o homem] viva bem, mas ao contrário, com que ele trabalhe de modo a tornar-se digno, por sua conduta, da vida e do bem-estar" ${ }^{13}$. Ora, se a natureza estivesse preocupada com que ele, o homem, vivesse bem, não guardaria a ele a possibilidade de desenvolver suas condições desde si

\footnotetext{
${ }^{13}$ KANT, Immanuel. Idéia de uma história desde um ponto de vista cosmopolita, $3^{*}$ proposição, pg. 12.
} 
mesmo - o que não se faz sem um esforço, pois é preciso querer dispondo o homem àquilo que lhe é próprio. Isso requer, não raro, a abdicação dos desejos, das inclinações e interesses em prol de um bem maior, que é o homem em sua possibilidade: ser-racional, ou ainda, a sua liberdade.

Ajusta-se a essa compreensão a quarta proposição de Idéia de uma história universal de um ponto de vista cosmopolita: "O meio de que a natureza se serve para realizar o desenvolvimento de todas as suas disposições é o antagonismo das mesmas na sociedade, na medida em que ele se torna ao fim a causa de uma ordem regulada por leis desta sociedade. Eu entendo por antagonismo a insociável sociabilidade dos homens, ou seja, a tendência dos mesmos a entrar em sociedade que está ligada a uma oposição geral que ameaça constantemente dissolver essa sociedade" ${ }^{14}$. Ora, se o homem é dotado de razão e por isso é capaz de conquistar por si mesmo a sua racionalidade, tornando-se, assim, um ser-racional, tal conquista é, ao mesmo tempo, o desenvolvimento de suas disposições e se dá de um modo: no âmbito da sociedade, na vida mesma enquanto a vida é vida em sociedade. $\mathrm{O}$ homem tende a associar-se por "sentir-se mais como homem" desse modo. Assim a vida torna-se mais fácil de que se ele estivesse só na floresta, por exemplo. Essa tendência justamente o opõe àqueles que the são semelhantes como num jogo de aproximação e afastamento, pois, ao mesmo tempo em que se opõem obstáculos à sua vontade, ele faz oposição à vontade alheia. É justamente por isso, todavia, que tal insociável sociabilidade serve como dispositivo para trazer à tona o que lhe é mais próprio, o que lhe constitui, sua disposição natural, que é poder desenvolver sua razão, racionalizando-se. Certamente é nesse jogo das vontades que a razão se faz premente, no qual não se pode prescindir de uma moral reguladora que, ao mesmo tempo, dispõe e permite ao homem o desenvolvimento pleno de si. Desse modo a moral não tem um papel meramente conservador, conciliador, mas sim constitui um optimum à vida, i.e., permite que esta se desenvolva em sua plenitude, que, no caso de um ser-racional, é a sua liberdade, sua autonomia. A moral seria então a condição necessária para o desenvolvimento e aperfeiçoamento do homem antes mesmo de adquirir um caráter coercitivo. Ainda assim, tal coerção consistiria na liberdade suprema de um ser-racional esclarecido que age por dever com vistas a um bem maior, o qual é justamente o desenvolvimento e a assunção de sua liberdade. A realização desta, da liberdade, num plano

${ }^{14}$ idem, 4 proposição, pg. 13. 
individual, meramente subjetivo, objetiva-se apenas num mundo inteligível, o qual é sempre um mundo possível, um reino dos fins que reúne justamente as condições de possibilidade de um ser-racional plenamente livre ou a perfeição plena de tais disposições.

Se se admite que tal desenvolvimento das disposições humanas tem como dispositivo a insociável sociabilidade dos homens supramencionada, teremos de admitir, também, tal movimento como um movimento progressivo do homem em direção a si mesmo. Segundo tal compreensão, Kant afirma que a realização plena de tais disposições do homem não se dá no indivíduo mas na espécie ${ }^{15}$, dentro de uma compreensão de uma história universal planificada. Quer dizer, uma história universal abarca uma compreensão de homem também universal. Partindo de uma compreensão de homem que seja universal - dotado de uma razão que impõe para si o desenvolvimento de suas disposições como plenificação do homem para si mesmo —, se o apreende num desenvolvimento progressivo em direção a si, a saber, à descoberta e desenvolvimento pleno de suas capacidades.

Compreende-se o passado como aquilo que conduziu o homem à tal posição, que permite saber de seu próprio desenvolvimento numa compreensão histórica. Ou seja, pelo modo como o homem sempre desenvolveu e tem aperfeiçoado seu talento e sua medida, pode-se estabelecer, compreender esse passado com vistas a um futuro. "A história, que se ocupa da narrativa dessas manifestações, por mais profundamente ocultas que possam estar as suas causas, permite todavia esperar que, com a observação, em linhas gerais, do jogo da liberdade da vontade humana, ela possa descobrir 'aí um curso regular - dessa forma, o que se mostra confuso e irregular nos sujeitos individuais poderá ser reconhecido, no conjunto da espécie, como um desenvolvimento continuamente progressivo, embora lento, das suas disposições originais" ${ }^{16}$. Chegou o instante no qual evolução histórica do homem revela-se segundo uma regularidade. Convoca-se a assumir sua própria constituição sob sua tutela, esclarecendose para si mesmo segundo suas possibilidades e condições. Desse modo, de fato, o homem realiza-se na imortalidade da espécie, na qual esta é justamente o meio de realização do indivíduo enquanto este é mortal e finito. A humanidade serve, desse modo, como meio justamente para poder realizar o mundo inteligivel pregado por Kant, no qual a liberdade dar-se-ia

\footnotetext{
15 idem, $2^{*}$ proposição, pg. 11.

${ }^{16}$ idem, introdução, pg.1.
} 
em sua disposição mais perfeita. O que só é possível porque há, nesse modo pelo qual o homem é, a mais profunda compreensão do progresso. A realização do desenvolvimento pleno das disposições originais do homem — por ser ele originariamente dotado de certas disposições - puderam ser desenvolvidas até o ponto no qual o homem depara-se com sua história, as quais requerem como meio, como dispositivo, a insociável sociabilidade dos homens. Dá-se um início "através de um progressivo iluminar-se (Aufklärung), a fundação de um modo de pensar que pode transformar, com o tempo, as toscas disposições naturais para o discernimento moral em princípios práticos determinados e assim finalmente transformar um acordo extorquido patologicamente para uma sociedade em um todo moral" 17 .

Nesse ponto da história encontra-se Kant. São essas as exigências de uma razão esclarecida que se fundamenta e se conquista a si mesma numa crítica, num critério que dá à própria razão a sua medida, o seu limite e, por conseguinte, as suas condições de possibilidade, que podem ser elevadas maximamente. $\mathrm{O}$ homem, finalmente, esclarece-se para si mesmo. Por isso pode-se escrever uma história universal de um ponto de vista cosmopolita que parece prescrever para uma história possível o que ela deve ser. Contudo, ao contrário, ele extrai da própria história o homem como um acontecimento histórico. Funda-se o homem na idéia de um progresso, num desenvolver-se lento e, nesse desenvolvimento, supõe-se um fim não no indivíduo mas na humanidade, quando esta é meio para a realização plena do homem num todo moral. Esta é, por isso, meio para que o indivíduo, que é mortal, se realize e, por isso mesmo, possa se realizar uma humanidade como meio para, novamente, ter lugar o individuo. Assim a espécie mantém-se em sua imortalidade, assim caminha o homem para a sua plena realização num todo moral esclarecido. Ao menos é essa a história que a História universal de um ponto de vista cosmopolita nos conta, cujo fundamento é, ainda, a liberdade da vontade.

\section{Referências Bibliográficas}

KANT, Immanuel. Crítica da Razão Pura. Lisboa: Fundação Calouste Gulbenkian, 1997.

. Crítica da Razão Prática. Lisboa: Edições 70, 1999.

Resposta à pergunta: o que é esclarecimento (Aufklärung)? In: Textos Seletos. Lisboa: edições 70,

${ }^{17}$ idem, $4^{*}$ proposição, pg. 13/14. 
. Idéia de uma história universal de um ponto de vista cosmopolita. Lisboa: Edições 70, . Fundamentos da metafísica dos costumes. Lisboa: ed. Didática, 1999.

Sobre a discordância entre a moral e a política a propósito da paz perpétua; in: A paz perpétua e outros opúsculos. Lisboa: Edições 70.

. LEBRUN, Gérard. Uma escatologia para a moral; in: Revista Manuscrito. Campinas: ed. Unicamp, 1979. 